\title{
Patient self management of anticoagulants resulted in fewer major complications than clinic-based management
}

Menéndez-Jándula B, Souto JC, Oliver A, et al. Comparing self-management of oral anticoagulant therapy with clinic management: a randomized trial. Ann Intern Med 2005;142:1-10.

Is patient self management of oral anticoagulants as efficacious and safe as management in an anticoagulation clinic?

METHODS

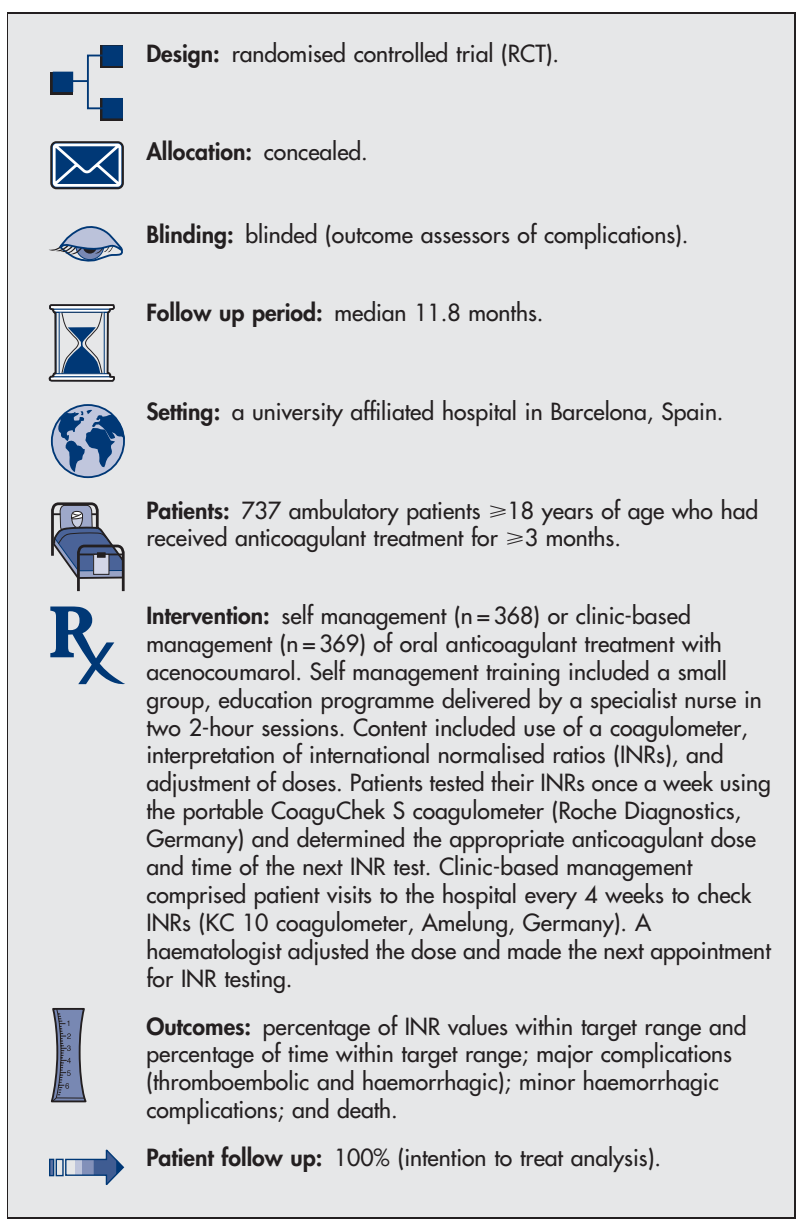

\section{MAIN RESULTS}

The self management group had a higher mean percentage of INR values within the target range than the clinic-based group $(58.6 \% \mathrm{v}$

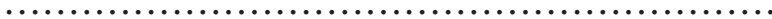
For correspondence: Dr J C Souto, Hospital de la Santa Creu i Sant Pau, Barcelona, Spain. jsouto@hsp.santpau.es

Source of funding: in part, Roche Diagnostic SL.
$55.6 \%$, mean difference $3.0 \%$, $95 \%$ CI 0.4 to 5.4 ). The groups did not differ for percentage of time within the target range $(64.3 \% \vee 64.9 \%$, $\mathrm{p}=0.2$ ). The self management group had lower rates of major, thromboembolic, and minor haemorrhagic complications, and death, but the groups did not differ for severe haemorrhagic complications (table).

\section{CONCLUSION}

Self management of oral anticoagulants resulted in fewer major complications than clinic-based management but similar levels of control.

A modified version of this abstract appears in ACP Journal Club.

\section{Commentary}

Dimpritien atient self management is more than just patient education to mprove compliance; patients become decision makers, are empowered in their disease management, and work in partnership with healthcare providers. ${ }^{1}$ Menéndez-Jándula et al found that patient self management resulted in similar physiological outcomes and fewer complications than usual care. These findings may be explained by the 3 fold increase in INR test frequency in the self management group, but Beyth et al also found improved outcomes when INR test frequencies were similar for self testing and control groups. ${ }^{2}$ Menéndez-Jándula et al therefore suggest that improved clinical outcomes were likely related to increased patient empowerment, adherence, and self awareness of health status.

Self management improves outcomes across a range of disease entities, but is it suitable for everyone? Menéndez-Jándula et al estimated that $50 \%$ of patients were able to safely use this strategy; the intervention group included many patients who were older or had lower levels of education. One-fifth of patients randomised to self management dropped out, a small proportion of whom were unable to attain sufficient skill levels. Although this does not affect the interpretation of the findings, it suggests that self management is not appropriate for all patients. RCTs of self management programmes have shown some positive results including reductions in hospital readmissions. ${ }^{3}{ }^{4} \mathrm{~A}$ cost effectiveness analysis would have been useful, although existing evidence suggests that self management could lead to substantial savings for the healthcare system. The coagulometers cost approximately US $\$ 1000$ per patient, and each reagent strip was approximately US $\$ 5$. This cost is prohibitive for many patients but may be justifiable public spending given the potential savings to the healthcare system. Further research on cost is required to provide the evidence required for policy change.

A Kirsten Woodend, RN, PhD University of OHtawa, OHtawa, Ontario, Canada

1 Tattersall RL. Clin Med 2002;2:227-9.

2 Beyth RJ, Quinn L, Landefeld CS. Ann Intern Med 2000;133:687-95.

3 Coleman EA, Smith JD, Frank JC, et al. J Am Geriatr Soc 2004;52:1817-25.

4 Gibson PG, Powell H, Coughlan J, et al. Cochrane Database Syst Rev 2003;(1):CD001117.

Self management $v$ clinic-based management of oral anticoagulant treatment ${ }^{*}$

\begin{tabular}{lccll}
\hline Outcomes at median $\mathbf{1 1 . 8}$ months & Self management & Clinic-based management & RRR (95\% Cl) & NNT (CI) \\
\hline Major complication & $2.2 \%$ & $7.3 \%$ & $70 \%(37$ to 86$)$ & 20 (12 to 46$)$ \\
Severe haemorrhagic complication & $1.1 \%$ & $1.9 \%$ & $43 \%(-82$ to 82$)$ & Not significant \\
Thromboembolic complication & $1.1 \%$ & $5.4 \%$ & $80 \%(45$ to 93$)$ & $23(14$ to 52$)$ \\
Minor haemorrhagic complication & $15 \%$ & $36 \%$ & $59 \%(46$ to 69$)$ & $5(4$ to 7$)$ \\
Death & $1.6 \%$ & $4.1 \%$ & $60 \%(1$ to 84$)$ & 41 (20 to 2994) \\
\hline
\end{tabular}

†Abbreviations defined in glossary; RRR, NNT, and Cl calculated from data in article. 